\title{
Influence of Aluminum at Low pH on the Rhizosphere Processes of Masson Pine (Pinus Massoniana Lamb)
}

\section{Wang Ping ( $\sim 18061713169 @ 163 . c o m$ )}

Nanjing Forestry University https://orcid.org/0000-0003-0452-922X

\section{Zhou Sijie}

Nanjing Forestry University

Li Ao

Nanjing Forestry University

\section{Xie Linbei}

Nanjing Forestry University

\section{Research Article}

Keywords: Aluminum toxicity, Low pH, Rhizosphere, Root-released compounds, Masson pine (Pinus massoniana L.)

Posted Date: July 21st, 2021

DOI: https://doi.org/10.21203/rs.3.rs-321670/v1

License: (9) This work is licensed under a Creative Commons Attribution 4.0 International License. Read Full License 
1 Influence of aluminum at low $\mathbf{p H}$ on the rhizosphere processes of 2 Masson Pine (Pinus massoniana Lamb)

3 Wang Ping ${ }^{1 I D} \cdot$ Zhou Sijie $^{1} \cdot$ Li Ao $^{1} \cdot$ Xie Linbei $^{1}$

$4 \bowtie$ Wang Ping

5 18061713169@163.com

$6 \quad{ }^{1}$ School of Biology and the Environment, Nanjing Forestry University, Nanjing 210037,

7 People's Republic of China 


\section{$8 \quad$ Abstract}

9 Trees in general are very tolerant of aluminum ( $\mathrm{Al}$, mainly $\mathrm{Al}^{3+}$ at $\left.\mathrm{pH} \leqq 5.0\right)$, and the small effects seen in the contaminated soils may mislead people that the contamination is unimportant. We believe that the assessments with Al-sensitive Masson pine could have

12 revealed a bigger difference. The key point of this study was to characterize the Al

13 toxicity for Masson Pine. The objectives were to discover the specific eco-physiological

14 relationship between pine roots and rhizosphere $\mathrm{Al}$, and to investigate the Al effects on

15 several parameters, measured in the rhizosphere of Masson pine. Masson pine seedlings

16 were cultivated on a hydroponic setup. Through comprehensive laboratory dose-gradient

17 experiments, Al-triggered composition of the root-released compounds and several

18 rhizospheric parameters were determined by chromatography or spectroscopy. This study

19 gives an important evidence of the Al-toxicity effects on the composition of root-released

20 compounds and the root growth of Masson pine. Results showed that higher rhizospheric

$21 \mathrm{Al}$ at $\mathrm{pH} 4.5$ might contribute to increased release of sugars, and also could stimulate the

22 release of oxalic acid and malic acid. The total of secreted amino acids were correlated

23 with the rhizosphere Al. Zero additional Al induced no rhizosphere $\mathrm{pH}$ elevation, but

24 Al-induced rhizosphere acidification ( $\mathrm{pH}$ from 4.50 to 4.22) was observed at $\mathrm{Al} 100 \mu \mathrm{M}$.

25 Greater additions of $\mathrm{Al}(>300 \mu \mathrm{M})$ suppressed the rhizosphere acidification at $\mathrm{pH} 3.92$.

26 Added Al had a negative effect on the dry weight of pine roots, but an opposite effect on

27 Al accumulated in the roots was observed. The four endogenous hormones were also

28 determined in the pine roots. Gibberellic acid $\left(\mathrm{GA}_{3}\right)$ decreased, whereas abscisic acid

29 (ABA) increased simultaneously with the addition of Al. Their inflexional concentrations

30 were most frequently observed at $100 \mu \mathrm{M}$, which might be the threshold of Al toxicity for 
31 Masson pine. The secondary metabolites assayed have been studied in relation to the

32 rhizospheric $\mathrm{Al}$. The rhizosphere $\mathrm{Al}$ species at low $\mathrm{pH}$ can trigger pine roots to release

33 the sugars (glucose, fructose + aldose), organic acids (oxalic acid, and malic acid), amino

34 acids, secondary metabolites, and endogenous hormones during their growth. Meanwhile

35 it also affected the growth of pine roots. This is an extensive study, which can help

36 understanding the toxicity of Al to this important pioneer species of acid forest soils in

37 south China.

38 Keywords Aluminum toxicity - Low $\mathrm{pH} \cdot$ Rhizosphere · Root-released

39 compounds · Masson pine (Pinus massoniana L.)

\section{Introduction}

41 Masson pine (Pinus massoniana Lamb) is a widely distributed native pioneer species,

42 which is grown on the acid forest soils in south China. This tree grows rapidly and is

43 economically important. It shows an inheritable tolerance to environmental stresses,

44 including acidic aluminum (Al) stress (Wu et al. 2009). Masson pine has shown

45 symptoms of die-back under the influence of atmospheric acid deposition. Acid

46 deposition has led to extensive soil acidification that comprise up to $50 \%$ of the world's

47 potentially arable lands. Phytotoxic $\mathrm{Al}$ ion (mainly $\mathrm{Al}^{3+}$ ) may threaten the integrity of

48 forest ecosystems as a result of acid deposition. Acidification may lead to forest soil

49 degradation, affecting the soil functions (Li et al. 2014). The Al released into the soil

50 solution is usually well below $50 \mu \mathrm{M}$ at $\mathrm{pH}>5.5$, but rises 100 -fold at $\mathrm{pH} 4.5$, which is

51 of risk for the growth of sensitive plant species (Wang et al. 2006; Yang et al. 2015).

52 High concentrations of Al may disrupt plant root functions and the metabolic changes 
53 associated with root-released compounds. The root system, especially root apex, is the 54 critical site for Al toxicity. Kidd et al. (2001) and Tolrà et al. (2005) wrote about maize 55 and Rumex acetosa L., respectively. Nowak and Friend (2005) also observed Al 56 resistance in the root tips of slash pine. Normally, plant roots excrete low molecular 57 weight organic molecules into plant rhizosphere to adapt various stressful circumstances. 58 Study of the root-released compounds holds great promise for revealing the effects of Al 59 on tree rhizosphere.

Rhizosphere is an important root-soil interface for releasing organic compounds, 61 intense nutrients exchange and microbial activity, and also a gateway for potentially toxic 62 pollutants such as $\mathrm{Al}$, in which normal root physiological action is greatly influenced by 63 root-released compounds (Hinsinger et al. 2005). Currently, the association between Al 64 chemistry of tree rhizosphere and soil acidification is an important concern (Rehmus et al. 65 2014; Hirano et al. 2012). Osawa and Matsumoto (2002) and Nguyen et al. (2003) 66 observed the effects of acid Al on rhizosphere ecological action. Several investigators 67 reported that the efflux of low molecular weight organic anions from root apices could 68 protect the root by chelating and thus detoxifying $\mathrm{Al}$ in the rhizosphere (Ma and 69 Furukawa 2003). Barceló and Poschenrieder (2002) reviewed immobilization of the cell 70 wall, selective permeability of the plasma membrane, formation of rhizosphere $\mathrm{pH}$ barrier 71 and evolution of Al-tolerant enzymes in higher plants under Al stress.

72 Numerous Al toxicity mechanisms have been proposed (Imadi et al. 2016). They can 73 be grouped into two categories: exclusion of $\mathrm{Al}$ from the roots, and detoxification of $\mathrm{Al}$ 74 ions in the plants (Poschenrieder et al.2008). Putative exclusion mechanisms proposed 75 include binding of $\mathrm{Al}$ in the cell wall, an Al-induced rhizosphere $\mathrm{pH}$ barrier, and 
76 root-released Al-chelating compounds (Ma and Furukawa 2003; Liang et al. 2013).

77 Organic acids have been suggested to play a role both in Al exclusion, via release from

78 the root, and Al detoxification in the apoplasm or rhizosphere, where low molecular

79 weight organic acids could chelate Al and reduce or prevent its toxic effects at the cellular

80 level (Zhang et al. 2014; Yang et al. 2017).

81 Trees in general are very tolerant of $\mathrm{Al}$, and the small effects seen in the contaminated

82 soils may mislead people that the contamination is unimportant. Our study found that the

83 assessments with Al-sensitive Masson pine would have revealed a bigger difference. The

84 purposes of this study were to assess the effects of $17 \mathrm{Al}$ levels at low $\mathrm{pH}$ in hydroponic

85 culture of Masson pine on the root growth, Al uptake and accumulation. The 17

86 dose-gradients of $\mathrm{Al}$ concentrations were selected from zero to $750 \mu \mathrm{M}$, based on our

87 earlier study (Wang et al. 2006; Wang et al. 2015b). Also, we measured the Al-induced

88 changes in the root-released compounds of sugars, organic acids, amino acids, secondary

89 metabolites, as well as rhizosphere $\mathrm{pH}$ and the endogenous hormones in the roots.

\section{Materials and methods}

\section{Seedling growth and treatment}

92 Seeds of Masson pine (China Zhejiang Forestry Science Institute) were surface-sterilized

93 in a $75 \%$ ethanol solution for $10 \mathrm{~min}$, rinsed in running tap water for $20 \mathrm{~min}$, and washed

94 with deionized water (Millipore, Eschborn, Germany) three times. Seeds were soaked in

95 deionized water for $24 \mathrm{~h}$, germinated for $48 \mathrm{~h}$, and then cultivated under a hydroponic

96 culture system. 
A $350 \mathrm{~L}$ nutrient solution containing the following concentrations of mineral was 98 prepared (in $\mu \mathrm{M}$ ): $250 \mathrm{NH}_{4} \mathrm{NO}_{3}, 60 \mathrm{KH}_{2} \mathrm{PO}_{4}, 220 \mathrm{~K}_{2} \mathrm{SO}_{4}, 188 \mathrm{CaCl}_{2}, 62 \mathrm{MgSO}_{4}$ and 95

99 100 101 102 103 104 105 106 107 108 109 110 111 Fe-EDTA, $46 \mathrm{H}_{3} \mathrm{BO}_{3}, 0.3 \mathrm{CuSO}_{4}, 0.1\left(\mathrm{NH}_{4}\right)_{6} \mathrm{Mo}_{7} \mathrm{O}_{24}, 9.2 \mathrm{MnSO}_{4}, 0.8 \mathrm{ZnSO}_{4}$ (van Schöll et al. 2005). The mixed solution was divided into 17 equal parts. Different amounts of $\mathrm{AlCl}_{3}$ were added to each part to reach concentrations of $0,7.5,15,30,45,60,75,100$, $150,200,250,300,350,400,450,600$ and $750 \mu \mathrm{M}$. Then the $\mathrm{pH}$ values of these solutions were initially adjusted to 4.5 using $\mathrm{HCl}$ or $\mathrm{NaOH}$ and checked and adjusted again three times a week. The nutrient solution without $\mathrm{Al}$ was used for control plants. The solutions were aerated by pumps, which connected the containers with pump lines. The nutrient solutions were changed regularly every 10 days. The seedlings from each treatment were harvested after $100 \mathrm{~d}$ of incubation for $\mathrm{Al}$ determination. To have Masson pine seedlings in a hydroponic and non-sterile system for 100 days, it is likely that contaminants such as fungi or bacteria can grow as well and establish on the root surface. Ultraviolet radiation was used to disinfect the growth chamber and the nutrient solutions prior to use.

The seedlings were transplanted into a $25-\mathrm{L}$ pot containing nutrient solutions (25 seedlings per pot) and incubated in a LRH-250-G growth chamber at $25 \pm 2{ }^{\circ} \mathrm{C}$. When the seedlings reached $8 \mathrm{~cm}$, they began to cultivate with the nutrient solutions containing different $\mathrm{Al}^{3+}$ concentrations. About $30 \mathrm{~mL}$ of fresh nutrient solution was added every 12 $\mathrm{h}$. The seedlings were grown in a controlled culture box with a $12 \mathrm{~h}$ light/12 h dark cycle under $40 \mathrm{~W} \mathrm{~m}^{-2}$ light. The light/dark temperatures were set at $25 / 20{ }^{\circ} \mathrm{C}$, and relative humidity was kept at $65 \%$. Concentrations of $\mathrm{Al}$ in the solution were measured and replenished every $12 \mathrm{~h}$. 
The root-released compounds were collected following the procedures described in

121 our previous studies (Wang et al. 2006; Wang et al. 2015b). Briefly, the roots were

122 treated with deionized water, and then exposed to a $1 \mathrm{~L} 0.5 \mathrm{mM} \mathrm{CaCl}_{2}$ solution ( $\mathrm{pH} 4.5$ )

123 with corresponding Al level for $24 \mathrm{~h}$ and then washed with $100 \mathrm{~mL}$ of deionized water

124 (25 seedlings per measurement). To avoid interaction between $\mathrm{Al}$ and other nutrients such

125 as $\mathrm{P}$, a simple salt solution containing $0.5 \mathrm{mM} \mathrm{CaCl}_{2}$ was used as the basal treatment. The

126 above-mentioned Al treatment solution was placed on a shaker, centrifugally separated

127 (60 rpm) for $2 \mathrm{~h}$, and filtered. The filtrate was divided into two equal parts. One part was

128 used to measure $\mathrm{pH}$, and the other part was concentrated to $50 \mathrm{~mL}$ under vacuum and

129 analyzed for sugars, amino acids, organic acids and secondary metabolites. The solution

130 pretreatment was performed at $4{ }^{\circ} \mathrm{C}$.

\section{Analysis}

132 Rhizosphere $\mathrm{pH}$

133 The $\mathrm{pH}$ electrode was placed in the filtrate, and $\mathrm{pH}$ value was read as soon as the PHS-25

134 pH-meter (Shanghai Precision Instruments Co., China) stabilized.

135 Sugar

136 A $5 \mathrm{~mL}$ filtrate was hydrolyzed with $10 \mathrm{~mL}$ of $4 \% \mathrm{H}_{2} \mathrm{SO}_{4}$ under vacuum at $110^{\circ} \mathrm{C}$ for $1 \mathrm{~h}$.

137 After cooling, the hydrolysate was washed with deionized water, filtered (Whatman No.2,

138 USA) and dried at $60{ }^{\circ} \mathrm{C}$ (also under vacuum) by a rotary evaporator. The dried sample

139 was then dissolved in $5 \mathrm{mMH}_{2} \mathrm{SO}_{4}$. The sugar (monosaccharide) in the hydrolysate was

140 separated and quantified by injecting $10 \mu \mathrm{L}$ into a HPLC (Waters 600 , USA) with RI $\times 4$

141 detector, equipped with a Sugar-pak ${ }^{\mathrm{TM}} 1$. P/N 85188 column (Waters, USA). The column 
142 temperature was $85^{\circ} \mathrm{C}$. Milli-Q water was used as the mobile phase with a flow rate of $1430.6 \mathrm{~mL} \mathrm{~min}^{-1}$.

144 Organic acids

145 The filtrate was passed through a cation exchange column $(16 \times 14 \mathrm{~mm})$ filled with $5 \mathrm{~g}$ of 146 Amberlite IR-120B resin $\left(\mathrm{H}^{+}\right.$form, Shanghai Chemical Reagent Co., China), followed by 147 an anion-exchange column $(16 \times 14 \mathrm{~mm})$ filled with $2 \mathrm{~g}$ of Dowex $1 \times 8$ resin (100-200 148 mesh, format form; Shanghai Chemical Reagent Co., China). The organic acids retained 149 on anion-exchange resin were eluted by $1 \mathrm{M} \mathrm{HCl}$, and the eluate was concentrated. $10 \mu \mathrm{L}$ 150 concentrating solution was injected onto an Aminex HPX-87H column $(7.8 \mathrm{~mm}$ i.d. $\times$ $151300 \mathrm{~mm}, 9 \mu \mathrm{m})$. The quantitative determination of organic acids was carried out with 152 electrospray ionization-tandem mass spectrometry (ASE-SPE-LC-ESI-MS/MS). The 153 mobile phase used was $5 \mathrm{mMH}_{2} \mathrm{SO}_{4}$ at a flow-rate of $0.5 \mathrm{~mL} \mathrm{~min}^{-1}$. Detection was at a 154 wavelength of $210 \mathrm{~nm}$. Column temperature was $50{ }^{\circ} \mathrm{C}$ (Wang et al. 2015a).

155 Amino acids

156 A $5 \mathrm{~mL}$ filtrate was hydrolyzed with $8 \mathrm{~mL}$ of $6 \mathrm{M} \mathrm{HCl}$ under vacuum at $110^{\circ} \mathrm{C}$ for $24 \mathrm{~h}$. 157 After cooling, the hydrolysate was washed with deionized water, filtered (Whatman No.2, 158 USA) and dried at $60{ }^{\circ} \mathrm{C}$ (under vacuum) by a rotary evaporator. The dried sample was 159 then dissolved in $0.01 \mathrm{M} \mathrm{HCl}$. The amino acids in the hydrolysate were separated and 160 quantified by injecting $50 \mu \mathrm{L}$ into a Hitachi 835-50 Amino Acid Automatic Analyzer 161 (Hitachi, Japan) equipped with a $2.6 \mathrm{~mm} \times 150 \mathrm{~mm}$ ion exchange column coated with 162 resin $2619^{\#}$. The column temperature was $53{ }^{\circ} \mathrm{C}$. Sodium citrate buffers (pH 3.3, 4.3, and 163 6.3) were used as eluents with a flow rate of $0.225 \mathrm{~mL} \mathrm{~min}^{-1}$. The light absorbance of the 164 amino acids was detected with a 166 Detector (Beckman Instruments) at $570 \mathrm{~nm}$. 
165 Secondary metabolites

166 Secondary metabolites were analyzed using a Finnigan Trace DSQ GC-MS (USA) in

167 selected ion mode (SIM). The capillary column used was a DB-5MS $(30 \mathrm{~m} \times 0.25 \mathrm{~mm}$ id $168 \times 0.25 \mu \mathrm{m}$ film thickness). The carrier gas was helium. A split/splitless injector in the 169 splitless mode was used. The inject volume was $1.0 \mu \mathrm{L}$ (Tikhomiroff and Jolicoeur 170 2002).

171 Aluminum

172 The fresh Masson pine roots were treated with deionized water (25 seedlings per 173 treatment) and cut into small pieces, which were dried at $70{ }^{\circ} \mathrm{C}$ for $48 \mathrm{~h}$ to determine their 174 dry weight (van Schöll et al. 2004). The dried roots were weighed, ground, acid-digested, 175 filtered, and finally concentrated to a certain volume. The total Al was determined by 176 inductively coupled plasma atomic emission spectrometer (ICP-AES, PS-1000AT, USA) 177 (Wang et al. 2012).

178 Endogenous hormones

179 Endogenous hormones were analyzed using a LC-ESI-MS/MS system. Ten $\mu \mathrm{L}$ of the 180 above-mentioned solution for Al determination was injected onto a KC-811 column. 181 Detection was at a wavelength of $254 \mathrm{~nm}$. The mobile phase used was a mixed solution 182 (methanol/water/acetic acid 50:49.3:0.7, V/V/V) at a flow rate of $0.6 \mathrm{~mL} \mathrm{~min}^{-1}$. Column 183 temperature was $35^{\circ} \mathrm{C}$. Quantification was based on the LC-ESI-MS/MS peak areas 184 found for the base peaks of single hormones (Wang et al. 2016). 


\section{Statistical analysis}

186 The data presented in Figures 1-4 were the mean and standard deviation (SD) of nine 187 replicated treatments (nine measurement, one measurement for one pot), which was an 188 expensive long-term experiment (from 2006 to 2018). Recovery of the 189 extraction/concentration procedure was evaluated. For each variable, the normality of the 190 distribution was tested with a Shapiro-Wilk test. Levels of significance were $P<0.0001$. 191 The wide range of $\mathrm{Al}$ concentration treatments tested was studied to analyze the 192 dose-response relationship. The curves trends, linear or quadratic, attached to the 193 response variables were observed in Figures 1-4.

\section{Results}

195 It was found that roots released organic acids; however, it was only known to a lesser 196 extent, that roots also released other compounds such as sugars, amino acids, or phenolic 197 compounds. Some of these organic molecules can bind Al and, thus, potentially detoxify 198 the phytotoxic $\mathrm{Al}$ ions. The detailed description for the experimental results was given in 199 the following sections.

\section{Al-triggered variation of root-released compounds}

201 Rhizosphere $\mathrm{pH}$

202 The variation of Al-contaminated rhizosphere $\mathrm{pH}$ was assessed in the presence and 203 absence of Al (Fig. 1a). At lower Al level $(100 \mu \mathrm{M})$, the addition of Al caused the 204 rhizosphere $\mathrm{pH}$ to decrease from 4.50 to 4.22. However, when Al level varied from 100 to 

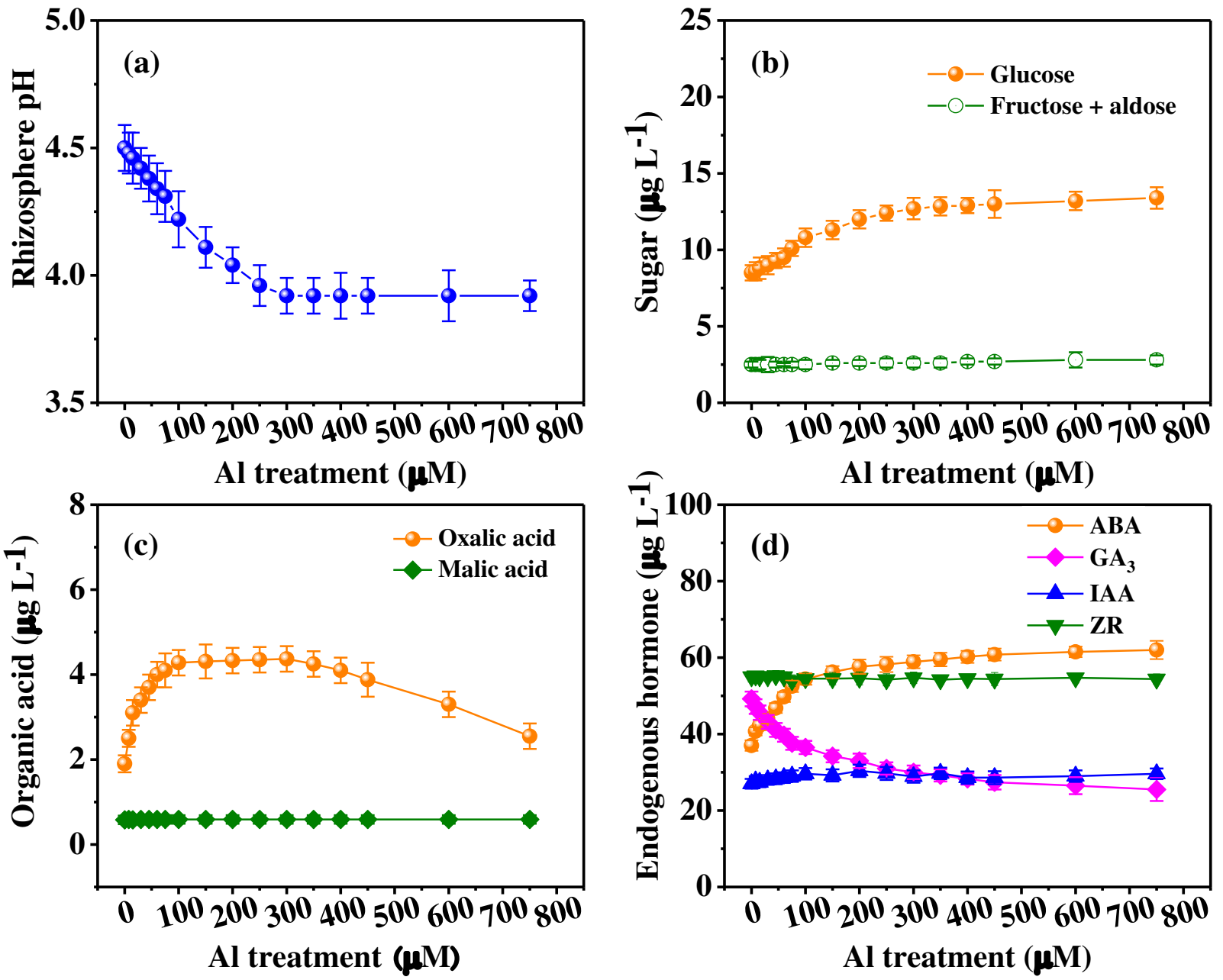

Fig. 1 Al-stimulated variation of the rhizosphere $\mathrm{pH}$ (a), sugars (glucose, fructose + aldose) (b), organic acids (oxalic and malic acids) (c), and endogenous hormones (d) released from Masson pine roots. All data present here are expressed as arithmetic means of nine observations \pm SD (standard deviation). Error bars represent SD from $n=9$ replicates.

\section{Sugars}

Glucose, fructose and aldose were identified in the root-released compounds. Only glucose was influenced by rhizosphere $\mathrm{Al}$ levels. Its concentrations increased proportionally with $\mathrm{Al}$ levels. When $\mathrm{Al}$ concentrations were varied from 0 to $100 \mu \mathrm{M}$, the 
218 increase in glucose was below $15 \%$, which was significantly different from the other

219 higher Al levels indicated in Fig. 1b. However, the released amounts of fructose and

220 aldose were very low in the given Al treatment range. No differences were found in the

221 release rates of fructose and aldose or the pattern of response to increasing $\mathrm{Al}$

222 concentrations.

223 Organic acids

224 Oxalic and malic acids were determined using ASE-SPE-LC-ESI-MS/MS system (Wang

225 et al. 2015a). The occurrence of Al-induced oxalic acid in the Masson pine rhizosphere

226 and its special relevance concerning Al levels were presented in Fig. 1c. Increasing

227 rhizosphere $\mathrm{Al}$ from 0 to $100 \mu \mathrm{M}$ slightly reduced the release of oxalic acid. Interestingly,

228 high $\mathrm{Al}^{3+}$ exposure $(>300 \mu \mathrm{M})$ triggered a significant small stimulation in oxalic acid. In

229 contrast, there was no clear varying trend for the root release of malic acid.

230 Amino acids

231 The effects of rhizosphere Al on the root-released amino acids were presented in Fig. 2.

232 In the blank assay, twelve amino acids, including alanine (Ala), asparagine (Asp), cystine 233 (Cys), glutamic acid (Glu), glycin (Gly), isoleucine (Ile), leucine (Leu), proline (Pro), 234 serine (Ser), threonine (Thr), tyrosine (Tyr) and valine (Val) were detected. Whereas 235 arginine (Arg), histidine (His), lysine (Lys), methionine (Met) and phenylalanine (Phe) 236 were not detected. However, with increased Al, Met, Phe, Arg, Lys and His became 237 detectable in succession and with the exception of Met and Arg, increased gradually, 238 while the release of Cys, Leu, Val and Pro decreased simultaneously. When the external 239 Al was in excess of $300 \mu \mathrm{M}$, Ser, Glu, Cys and Asp were undectable. But, the 240 Al-triggered release of aromatic Tyr and Phe rose steeply with Al concentrations. 

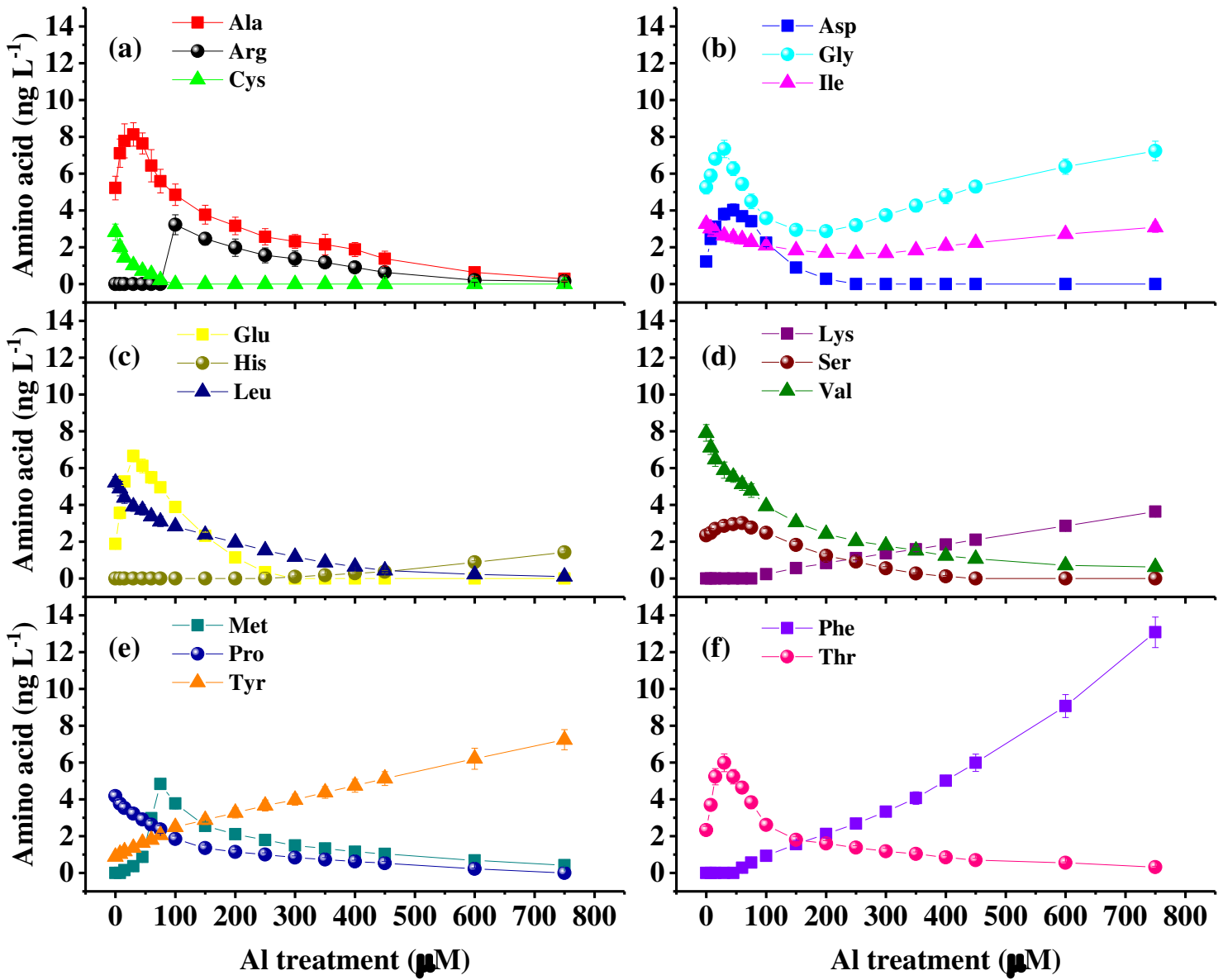

Fig. 2 Al-stimulated amino acids released from Masson pine roots. Herein, (a) for Ala (alanine), Arg (arginine) and Cys (cystine); (b) for Asp (asparagine), Gly (glycin) and Ile (isoleucine); (c) for Glu (glutamic acid), His (histidine) and Leu (leucine); (d) for Lys (lysine), Ser (serine) and Val (valine); (e) for Met (methionine), Pro (proline) and Tyr (tyrosine); (f) for Phe (phenylalanine) and Thr (threonine). Error bars represented SD from $n=9$ replicates.

\section{Secondary metabolites}

The results presented in Fig. 3 indicated that the release of secondary metabolites was greatly influenced by acidic rhizospheric Al. In the blank assay, cyclohexanol, cyclohexanone, 6-methyl-2-methyl-dicyclo(3,1,1)heptane, methylnaphthalene, 2,6-ditert-butylphenol, 2-ethyl-1,3-dimethylbenzene, 1,2,3,4-tetramethylbenzene, 10-methyl-methyl hendecylate, $\beta$-phellandrene and n-dotriacontane, were released from 
255 the pine roots. However, in the Al-treated rhizosphere, detectable secondary metabolites

256 were: cyclohexanol, cyclohexanone, methylnaphthalene, 2-ethyl-1,3-dimethylbenzene,

257 10-methyl-methyl hendecylate, n-dotriacontane, 3-methyl-furandione(2,5),

258 N,N'-ethyldiglycin, 1,2,3,5-tetramethylbenzene, pentanal, pentadiene-(1,4),

259 5-nitrylpyrazole, cyclobutanol-6-methylheptyl amine-2 and 2-nitryl-1-caprolene-4-alkyne.

260 With increasing rhizosphere $\mathrm{Al}^{3+}$, the eight secondary metabolites gradually disappeared.

261 Simultaneously, the eight new secondary metabolites were successively released. When

262 Al-treated concentration was $750 \mu \mathrm{M}$, only cyclohexanol, cyclohexanone, and

263 2-nitryl-1-caprolene-4-alkyne were detected.

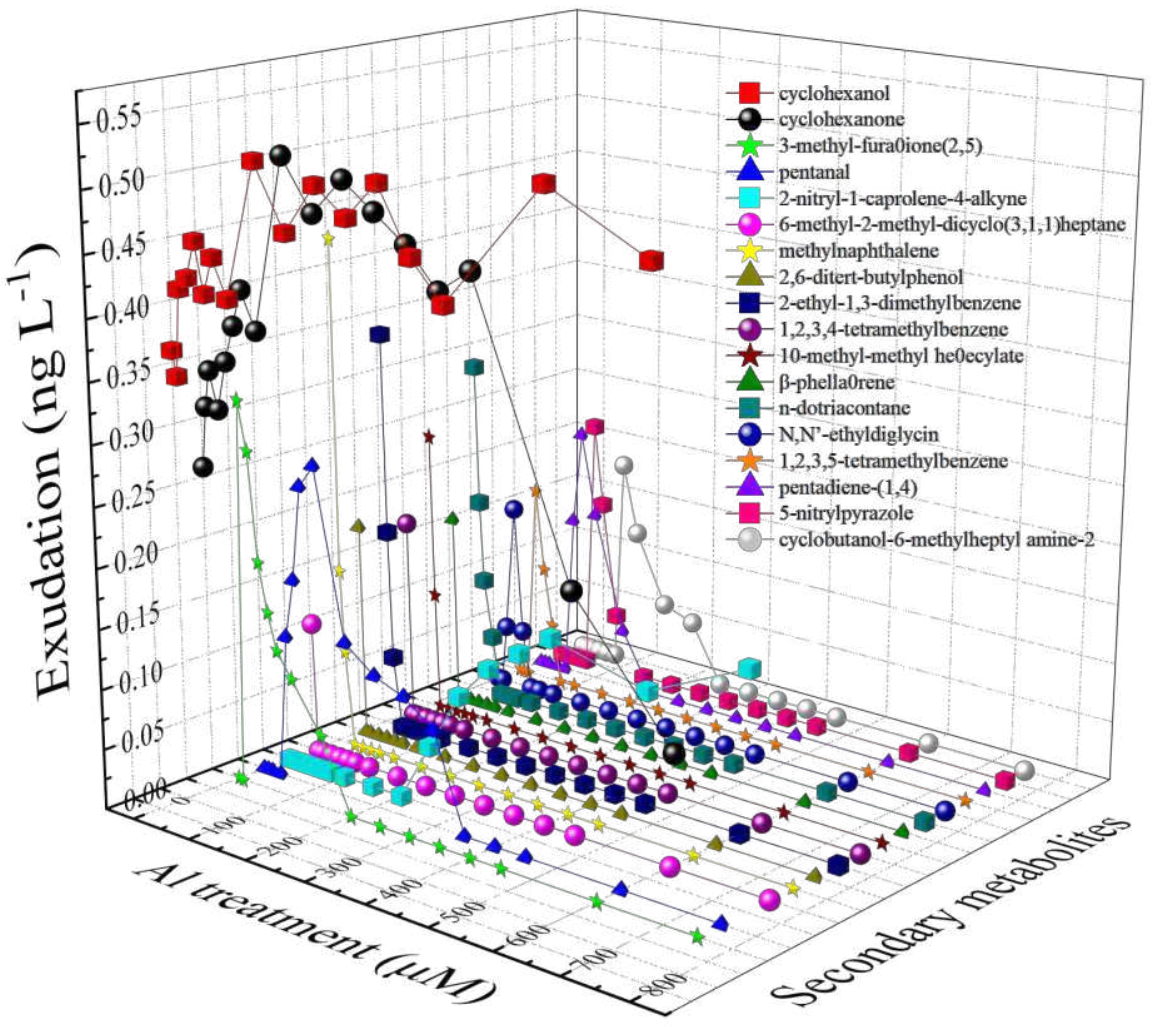

Fig. 3 Effects of rhizosphere $\mathrm{Al}$ on the secondary metabolites (ng $\mathrm{L}^{-1}$ ) exuded from Masson pine roots. The data shown in Fig. 3 was the mean and standard deviation (SD) of nine replicated treatments. 


\section{Al-triggered influence on the pine roots}

269 Endogenous hormones

270 The endogenous hormones, abscisic acid (ABA), gibberellic acid $\left(\mathrm{GA}_{3}\right)$, indole-3-acetic 271 acid (IAA) and zeatin riboside (ZR), were detected using ASE-SPE-LC-ESI-MS/MS 272 methodology (Wang et al. 2016). As shown in Fig. 1d, a higher level of ABA in the pine 273 roots was observed in the positive response to increasing external Al. In contrast, the 274 Al-induced negative response of $\mathrm{GA}_{3}$ was observed to increasing external $\mathrm{Al}$, its 275 maximum concentration occurred at zero Al treatment. For IAA and ZR, they seem have 276 no effect on the Al detoxicity of pine roots. Their levels were characterized by ZR > IAA 277 throughout the experiment.

278 Root dry weight and accumulated Al

279 Figure 4a demonstrated that Masson pine root growth was inhibited by increasing $\mathrm{Al}$ 280 concentrations. Accurately, added Al had a negative effect on the root dry weight. The 281 linear equation used for the estimations of root dry weight was as follows:

$282 \mathrm{Wt}=0.255-2.38 \mathrm{E}^{-4} \times \mathrm{C}_{\mathrm{Al}} \quad \mathrm{R}^{2}=0.983 \quad P<0.0001 \quad$ (Eq. 1)

283 where $\mathrm{Wt}$ is the dry weight of pine root $\left(\mathrm{mg} \mathrm{g}^{-1} \mathrm{dw}\right)$, and $\mathrm{C}_{\mathrm{Al}}$ is the Al-treated 284 concentration $(\mu \mathrm{M})$.

285 Meanwhile, added Al had a positive effect on the Al contents accumulated in the 286 pine roots (Fig. 4b). When Al-treated concentration was more than $300 \mu \mathrm{M}$, the Al 287 accumulated contents increased gradually from 2.5 to $8.3 \mu \mathrm{g} \mathrm{g}^{-1} \mathrm{dw}$. The Al accumulated 288 contents can be calculated as follows:

$289 \quad \mathrm{Q}_{\mathrm{Alac}}=0.104+0.0096 \times \mathrm{C}_{\mathrm{Al}} \quad \mathrm{R}^{2}=0.985 \quad P<0.0001 \quad$ (Eq. 2) 
290 where $\mathrm{Q}_{\mathrm{Alac}}$ is the $\mathrm{Al}$ content accumulated in the pine roots $\left(\mu \mathrm{g} \mathrm{g} \mathrm{g}^{-1} \mathrm{dw}\right.$ ), and $\mathrm{C}_{\mathrm{Al}}$ is the 291 Al-treated concentration $(\mu \mathrm{M})$.

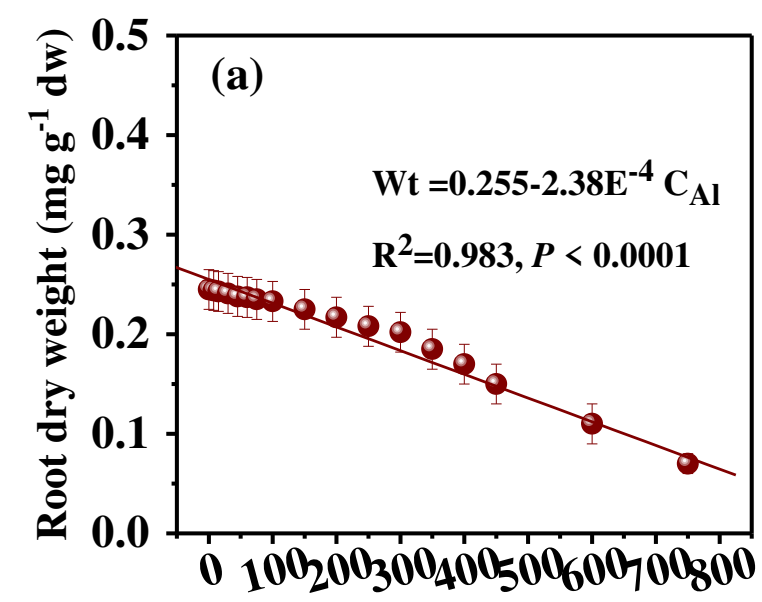

Al treatment (pM)

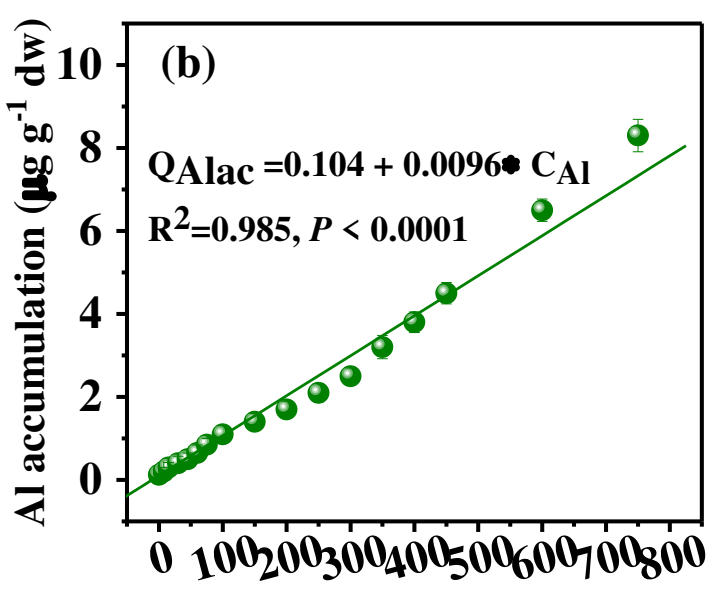

Al treatment ( $\mathbf{M M})$
292

293

294

295

296

297

298

299

300

301

302

303

304

Fig. 4 Al-stimulated variations of root dry weight (a) and the Al accumulated in Masson pine roots (b). Error bars represent SD from $n=9$ replicates.

\section{Discussion}

An increased understanding of the Al-tolerant rhizosphere processes can help in the growth of Masson pine that is adapted to acidic soils (Wu et al. 2009). Our work emphasizes Masson pine's response to rhizosphere Al.

Al-stimulated root-released compounds are a useful system for studying how the Al signal expresses physiological responses underlying Al tolerance, and we believe that their compositional changes play a significant role in the transduction of Al signals in the root apex of Masson pine. In general, plants may produce more root-released compounds under environmental stress (Hinsinger et al. 2005). The root-released compounds mainly were electrolytes, $\mathrm{H}^{+}$, sugar, organic acids, amino acids and other secondary metabolites. 
305 We really want to perform a comprehensive analysis of the root-released compounds.

306 Due to the limitation of instrument sensitivity, we could only detect these compounds at 307 present, although we try to figure out every peak detected via our analytical instruments 308 including HPLC, GC-MS and LC-MS. Several studies also support a mechanism 309 whereby in the plant-soil interface, active Al ions chelate with root-released organic 310 compounds to alleviate Al toxicity (Eticha et al. 2005). However, the specific 311 mechanisms of Al toxicity are still poorly understood in tree species. Following is the 312 discussion on the characterization of Al toxicity for Masson pine, which will benefit the 313 understanding of the Al-tolerant mechanism of Masson pine.

314 Variation of rhizospheric $\mathrm{pH}$

315 Evidence also exists to show that rhizosphere $\mathrm{pH}$ is primarily caused by root and 316 microbial respiration, unbalanced uptake of inorganic anions and cations, release of 317 organic anions and oxidation of soil minerals (Hinsinger et al. 2005). This Al-induced 318 acidification possibly occurs as a consequence of differential rates in the uptake of 319 cations and anions by Masson pine roots. The excess of $\mathrm{H}^{+}$to counterbalance a lack 320 uptake of $\mathrm{Al}$ over anions (mainly $\mathrm{OH}^{-}$) has caused a rapid decrease in rhizosphere $\mathrm{pH}$ 321 (0.58 pH, Fig. 1a). The ability to acidify the root medium may be genetic, relating to 322 physiological adaptation and Al tolerance (Haruta and Constabel 2003). It was found that $323 \mathrm{Al}$ exposure elicited changes both in root organic acid content and rhizosphere $\mathrm{H}^{+}$release 324 (Zhang et al. 2019). Acidification at the root surface increases the activity of rhizotoxic 325 Al ions, which might partly affect the toxic effects of Al on tree species (Hirano et al. 326 2012; Rehmus et al. 2014). This effectiveness of rhizosphere acidification in alleviating 327 Al toxicity has also been demonstrated by root release of oxalic acid which can chelate 
328 and detoxify excessive Al in the apoplasm or rhizosphere (Liang et al. 2013). Thus, 329 rhizosphere $\mathrm{pH}$ can negatively affect the activity of phytotoxic Al ions, which might 330 partly alleviate the toxic effects of $\mathrm{Al}$ on tree species.

331 Sugar and organic acids released from the pine roots

332 The results in Fig. 1b showed that the addition of $\mathrm{Al}$ had a positive effect on the secretion 333 of glucose. In contrast, the concentrations of fructose and aldose were very low during 334 the entire experimental assay. The relatively high Al-stimulated release of glucose can be 335 explained by the fact that $\mathrm{Al}$ affects adaptive reactions relating to carbon metabolism. 336 Root-released glucose may be perhaps related to selective permeability of the plasma 337 membrane. The root-released organic acids are another observed physiological change in 338 response to added $\mathrm{Al}$. The results in Fig. 1c showed that Al quantitatively stimulates the 339 efflux of oxalic acid from excised root apices of the pine seedlings. Clearly, organic acids 340 have been directly implicated in a number of rhizosphere processes such as 341 Al-detoxification and nutrient solubilization by roots. The Al-induced secretion of oxalic 342 acid has been reported as an Al-tolerance mechanism by Li et al. (2000). Their direct role 343 in these rhizosphere processes, however, has been difficult to establish due to the many 344 interdependent factors influencing the release of organic acids. These factors include 345 solid phase sorption/desorption reactions, metal complexation reactions, leaching and 346 microbial degradation (Ramesh et al. 2018). The present results confirm that in Masson 347 pine, as in other herb, the release of an $\mathrm{Al}$ chelator might partly alleviate the toxic effects 348 of $\mathrm{Al}$ on tree species.

349 Amino acids and secondary metabolites released from the pine roots 
350 Rhizosphere Al affected amino acid secretion, making several original amino acids 351 disappear and some new amino acids appear (see Fig. 2). This indicated that Al-triggered 352 release of amino acids was different from the results of controls. Interestingly, Al 353 exposure triggered much a small stimulation in certain amino acids and cause severe 354 physiological disorders in Masson pine. We obtained 17 dose-response curves relating 355 root apical amino acids release to Al activity. These responses were interpreted as the 356 result of Al-induced environmental stress.

357 The composition of secondary metabolites released from the roots was different in the 358 presence of Al. Some original secondary metabolites detected in the blank assay were not, 359 however, observed under condition of Al treatments, while there were some new 360 secondary metabolites to be later found. What is the difference between original 361 secondary metabolites and new secondary metabolites? These new secondary metabolites 362 are an interesting response to the addition of $\mathrm{Al}$, having developed strategies to avoid or 363 tolerate Al-induced effects, and progressively stimulate Masson pine to grow under Al 364 enhanced conditions. The increased root-released metabolites can be explained by the 365 disorganization of the physiological functions of fine roots that cannot prevent the 366 leaking out of sugars, amino acids and other important compounds, such as secondary 367 metabolites (Bourgaud et al. 2001). More information has to be included about 368 transporters and ion channels, which could give hints on the release of organic secondary 369 metabolites from the roots. Chen et al. (2006) revealed that these molecules contribute to 370 plant fitness by interacting with the ecosystems.

371 Endogenous hormones in the pine roots 
372 As shown in Fig. 1d, the rooting response of $\mathrm{ABA}, \mathrm{GA}_{3}$, IAA, and $\mathrm{ZR}$ to increased levels

373 of $\mathrm{Al}$ ion was examined. Preliminary studies indicate that these endogenous hormones are

374 regulators produced by plants themselves, as a minor component of the metabolome,

375 which control the physiological processes and are of particular significance given their

376 role in the protective responses of plants against stress (Haruta and Constabel 2003).

377 During plant growth, $\mathrm{ABA}$, as a stress hormone, has been shown to play a central role in

378 adaptive responses to environmental stress (Zhang et al. 2018). We obtained a direct

379 relationship between these detected hormones and high-Al tolerance. The significant

380 variation of $\mathrm{ABA}$ and $\mathrm{GA}_{3}$ in $\mathrm{Al}$-treated roots seems to be associated with $\mathrm{Al}$ response,

381 but the opposite responses to $\mathrm{Al}$ were observed for $\mathrm{ABA}$ and $\mathrm{GA}_{3}$. This possibility of the

382 interpretation will be the focus of future work in our laboratory.

383 Absorption of Al by Masson pine roots and root growth

$384 \mathrm{Al}$ accumulation in Masson pine roots under normal growth conditions was relatively low, 385 with an average concentration of $0.1 \mu \mathrm{g} \mathrm{g}^{-1} \mathrm{dw}$. Most trees contain no more than $0.2 \mu \mathrm{g}$ $386 \mathrm{~g}^{-1} \mathrm{dw}$ of $\mathrm{Al}$ (Zhang et al. 2014). The $\mathrm{Al}^{3+}$ accumulated in root systems is influenced by 387 many factors, such as transpiration (the rate of moisture absorbed by roots), coefficient of 388 ionic diffusion (ionic migration and solubility), concentration gradient, and other ions in 389 the root system (Kopittke et al. 2015). The Al influx finally reaches the root system, and 390 is accumulated in the pine roots, around the cortex. The initial and most dramatic 391 symptom of $\mathrm{Al}$ accumulated in roots results in a reduced root system 392 (Mossor-Pietraszewska 2001). Long-term exposure to Al, such as 100 days, will lead to 393 nutrient deficiencies, mainly of $\mathrm{P}, \mathrm{K}, \mathrm{Ca}$ and $\mathrm{Mg}$, and then inhibition of root growth 
394 generally (Vitorello et al. 2005; Schaberg et al. 2006; Zhang et al. 2019). Barceló and 395 Poschenrieder (2002) observed that root growth is immune to lower level additions of Al.

396 Inferred from the significant decrease of root dry weights at Al levels from $300 \mu \mathrm{M}$ 397 to $750 \mu \mathrm{M}$ (Fig. 3a), these pine seedlings were undergoing severe Al stress. Although 398 there is no direct link between changes in the rooting Al accumulation and alleviation of 399 root growth inhibition, our interpretation is that higher Al strongly impacts root cell 400 membrane integrity and favors the leak of root cell solutes, which results in obvious 401 decreases in the root growth (Kopittke et al. 2015; Zhang et al. 2018).

402 Mechanisms underlying Al-tolerance based on this Masson pine case-study

403 (1) Inhibition of root growth is a well-known effect of Al toxicity, and root tips have 404 been suggested as a primary site for Al-induced injury in plants. The rhizosphere 405 response to increased levels of $\mathrm{Al}$ in a hydroponic setup behaved differently in the 406 composition of root-released compounds, root growth inhibition and rooting $\mathrm{Al}$ 407 accumulation. Al resistance is related to rhizosphere $\mathrm{Al}$ ion concentrations and is 408 characterized by $\mathrm{Al}$ exclusion from the root tip, changes in rhizosphere $\mathrm{pH}$, and increased 409 release of organic acids (Imadi et al. 2016).

410 (2) The pine seedlings emitted different physiological signal in response to Al 411 exposure in their rhizosphere (Wu et al. 2009). Many compounds released from the pine 412 roots (such as electrolyte, $\mathrm{H}^{+}$, sugar, organic acids, amino acids, endogenous hormones, 413 enzymes and other secondary metabolites) react or balance with external Al ions to 414 alleviate Al toxicity. The composition of root-released compounds is related to 415 Al-resistance (Hinsinger et al. 2005). The observed Al-induced changes in the 
416 root-released compounds are a response to $\mathrm{Al}$ that could contribute to alleviate $\mathrm{Al}$ 417 toxicity.

418 (3) Finally, Al stimulates the efflux of oxalic acid by activation of anions channels 419 (Piñeros et al. 2002). Activation of anion efflux channels facilitating the efflux of oxalic 420 acid seems responsible for Al resistance (Poschenrieder et al. 2008). The Al-induced 421 organic acid anions are transported through the specific anion channel across the plasma 422 membrane into plant rhizosphere, which makes the plasma membrane positively charged 423 and rejects external $\mathrm{Al}^{3+}$ (Ohno et al. 2003) as well as $\mathrm{H}^{+}$(Zhang et al. 2019). The oxalic 424 acid stained inside root tip may react with smaller amounts of Al. These complexes are 425 not toxic to plant cells (Wenzl et al. 2002). Outside Masson pine roots, the secreted oxalic 426 acid reacts or balances with external A1 to obtain Al tolerance (Wang et al. 2020). The 427 stable Al-organic acid complexes do not across rooting plasma membrane (Kinraide et al. 428 2005) and cannot be accumulated the pine roots, which could contribute to alleviate Al 429 toxicity.

430 Phytotoxic effects of Al in acidic soil on Masson pine destroy many physiological 431 and biochemical pathways occurring in roots, and results in Al uptake and exudation of 432 various compounds (Imadi et al. 2016; Yang et al. 2017). Herein, this root/rhizospheric 433 responses to Al-toxicity were observed comprehensively. We anticipate that our 434 experimental data-set will further enhance our understanding of the bigger picture about 435 Al-toxicity/Al-tolerance/Al-adaptation of forests impacted by acidification. 


\section{Conclusions}

437 In summary, the present study using a hydroponic technique revealed the characterization 438 of Al toxicity for Masson Pine through comprehensive laboratory dose-gradient 439 experiments. Here, we observed that Al tolerant species tend to acidify their apoplast 440 (rhizosphere $\mathrm{pH}$ from 4.50 to 3.92). Higher Al-treated concentrations at low $\mathrm{pH}$ 441 contributed to changes in the composition of root-released compounds (oxalic acid, 442 sugars, amino acids, endogenous hormones and secondary metabolites), Al uptake and 443 accumulation, root growth of Masson pine cultivar. The pine root defense system 444 gradually shows an inheritable tolerance to a broad range of rhizosphere Al 445 concentrations. The observed dose-responses of root-released compounds to Al could 446 contribute to alleviate Al toxicity. It is possible to derive dose-response models to 447 calculate thresholds for Al toxicity based on growth or changes in metabolic profiles. Our 448 results highlight the importance of rhizospheric release and regulatory processes, which 449 may play an important combined role in regulating Al-resistance of Pinus nassoniana, as 450 for how they modulated these rhizospheric processes is in progress. Additionally, 451 exposure to $\mathrm{Al}$ also influences $\mathrm{H}^{+}$-adenosine triphosphatase $\left(\mathrm{H}^{+}\right.$-ATPase) activity in 452 Masson pine (Minorsky 2019). The biochemistry of $\mathrm{Al}$ and the $\mathrm{H}^{+}$-ATPase mechanisms 453 by which it affects Al tolerance need to be investigated in future.

\section{Author information}

455 Corresponding Author

456 *E-mail: 18061713169@163.com.

\section{Disclosure statement}

458 No potential conflict of interest was reported by the authors. 
Acknowledgements This work was financially supported by the Natural Science Foundation of China $(30771696 ; 31270680)$. We thank the many graduate students for their assistance with this work.

\section{References}

Barceló J, Poschenrieder C (2002) Fast root growth responses, root exudates, and internal detoxification as clues to the mechanisms of aluminium toxicity and resistance: a review. Environ Exp Bot 48: 75-92

Bourgaud F, Gravot A, Milesi S, Gontier E (2001) Production of plant secondary metabolites: a historical perspective. Plant Sci 161: 839-851

Chen YM, Wang MK, Zhuang SY, Chiang PN (2006) Chemical and physical properties of rhizosphere and bulk soils of three tea plants cultivated in Ultisols. Geoderma 136: 378-387

Eticha D, Thé C, Welcker C, Narro L, Stass A, Horst WJ (2005) Aluminum-induced callose formation in root apices: inheritance and selection trait for adaptation of tropical maize to acid soils. Field Crops Res 93: 252-263

Haruta M, Constabel CP (2003) Rapid alkalinization factors in poplar cell cultures. Peptide isolation, cDNA cloning, and differential expression in leaves and methyl jasmonate-treated cells. Plant Physiol 131: 814-823

Hinsinger P, Plassard C, Jaillard B (2005) Rhizosphere: A new frontier for soil biogeochemistry. J Geochem Explor 88: 210-213

Hirano Y, Frey B, Brunner I (2012) Contrasting reactions of roots of two coniferous tree species to aluminum stress. Environ Exp Bot 77: 12-18

Imadi SR, Waseem S, Kazi AG, Azooz MM, Ahmad P (2016) Aluminum toxicity in plants: an overview. Plant Metal Interaction, Elsevier, pp: 1-20

Kidd PS, Llugany M, Poschenrieder C, Gunsé B, Barceló J (2001) The role of root exudates in aluminum resistance and silicon-induced amelioration of aluminum toxicity in three varieties of maize (Zea mays L.). J Exp Bot 52: 1339-1352

Kinraide TB, Parker DR, Zobel RW (2005) Organic acid secretion as a mechanism of aluminum resistance: a model incorporating the root cortex, epidermis, and the external unstirred layer. J Exp Bot 56: 1853-1865

Kopittke PM, Moore KL, Lombi E, Gianoncelli A, Ferguson BJ, Blamey FPC, Menzies NW, Nicholson TM, McKenna BA, Wang P, Gresshoff PM, Kourousias G, Webb 
RI, Green K, Tollenaere A (2015) Identification of the primary lesion of toxic aluminum in plant roots. Plant Physiol 167: 1402-1411.

Li XF, Ma JF, Matsumoto H (2000) Pattern of aluminum-induced secretion of organic acids differs between rye and wheat. Plant Physiol 123: 1537-1543

Liang C, Piñeros MA, Tian J, Yao Z, Sun L, Liu J, Shaff J, Coluccio A, Kochian LV, Liao H (2013) Low pH, aluminum, and phosphorus coordinately regulate malate exudation through GmALMT1 to improve soybean adaptation to acid soils. Plant Physiol 161: 1347-1361.

Ma JF, Furukawa J (2003) Recent progress in the research of external Al detoxification in higher plants: a minireview. J Inorg Biochem 97: 46-51

Minorsky PV (2019) Vacuolar $\mathrm{H}^{+}$-ATPase regulates Al resistance. Plant Physiol181: 382.

Mossor-Pietraszewska T (2001) Effect of aluminum on plant growth and metabolism. Acta Biochim Pol 48: 673-686

Nguyen NT, Nakabayashi K, Thompson J, Fujita K (2003) Role of exudation of organic acids and phosphate in aluminum tolerance of four tropical woody species. Tree Physiol 23: 1041-1050

Nowak J, Friend AL (2005) Aluminum fractions in root tips of slash pine and loblolly pine families differing in Al resistance. Tree Physiol 25: 245-250

Ohno T, Koyama H, Hara T (2003) Characterization of citrate transport through the plasma membrane in a carrot mutant cell line with enhanced citrate excretion. Plant Cell Physiol 44: 156-162

Osawa H, Matsumoto H (2002) Aluminum triggers malate-independent potassium release via ion channels from the root apex in wheat. Planta 215: 405-412

Piñeros MA, Magalhaes JV, Alves VMC, Kochian LV (2002) The physiology and biophysics of aluminum tolerance mechanism based on root citrate exudation in Maize. Plant Physiol 129: 1194-1206

Poschenrieder C, Gunsé B, Corrales, I, Barceló J (2008) A glance into aluminum toxicity and resistance in plants. Sci Total Environ. 400: 356-368

Ramesh SA, Kamran M, Sullivan W, Chirkova L, Okamoto M, Degryse F, McLaughlin M, Gilliham M, Tyerman SD (2018) Aluminum-activated malate transporters can facilitate GABA transport. Plant Cell 30: 1147-1164.

Rehmus A, Bigalke M, Valarezo C, Castillo JM, Wilcke W (2014) Aluminum toxicity to tropical montane forest tree seedlings in southern Ecuador: response of biomass and plant morphology to elevated Al concentrations. Plant Soil 382: 301-315 
Schaberg PG, Tilley JW, Hawley GJ, DeHayes DH, Bailey SW (2006) Associations of calcium and aluminum with the growth and health of sugar maple trees in Vermont. For Ecol Manage 223: 159-169

Tikhomiroff C, Jolicoeur M (2002) Screening of Catharanthus roseus secondary metabolites by high-performance liquid chromatography. J Chromatogr A 955: $87-93$

Tolrà RP, Poschenrieder C, Luppi B, Barceló J (2005) Aluminium-induced changes in the profiles of both organic acids and phenolic substances underlie Al tolerance in Rumex acetosa L. Environ Exp Bot 54: 231-238

van Schöll L, Keltjens WG, Hoffland E, Breemen NV (2004) Aluminium concentration versus the base cation to aluminium ratio as predictors for aluminium toxicity in Pinus sylvestris and Picea abies seedlings. For Ecol Manage 195: 301-309

van Schöll L, Keltjens WG, Hoffland E, Breemen NV (2005) Effect of ectomycorrhizal colonization on the uptake of $\mathrm{Ca}, \mathrm{Mg}$ and $\mathrm{Al}$ by Pinus sylvestris under aluminium toxicity. For Ecol Manage 215: 352-360

Vitorello VA, Capaldi FR, Stefanuto VA (2005) Recent advances in aluminum toxicity and resistance in high plants. Brazilian J Plant Physiol 17: 129-143

Wang P, Bi SP, Ma LP, Han WY (2006) Aluminum tolerance of two wheat cultivars (Brevor and Atlas 66) in relation to their rhizosphere $\mathrm{pH}$ and organic acids exuded from roots. J Agric Food Chem 54: 10033-10039

Wang P, Zhou S, Zhang M (2020) Occurrence of endogenous hormones in the roots of Masson pine (Pinus massoniana Lamb.) seedlings subjected to aluminum stress under the influence of acid deposition. Plant Growth Regul 92: 43-52.

Wang SL, Chen LW, Fan CQ, Wang P (2016) Determination of abscisic acid, gibberellic acid, indole-3-acetic acid, and zeatin riboside in Masson pine (Pinus massoniana L.) by Accelerated Solvent Extraction and High-Performance Liquid Chromatography-Tandem Mass Spectrometry. Anal Lett 49(13): 1986-1996

Wang SL, Fan CQ, Wang P (2015a) Determination of ultra-trace organic acids in Masson pine (Pinus massoniana L.) by accelerated solvent extraction and liquid chromatography-tandem mass spectrometry. J Chromatogr B 981-982: 1-8

Wang SL, Wang P, Fan CQ (2015b) Distribution of aluminum fractionation in the acidic rhizosphere soils of Masson pine (Pinus massoniana L.). Commun Soil Sci Plan 46: 2033-2050

Wang SL, Wang P, Fan CQ, Xu H (2012) Phytoavailability and speciation of aluminum carried by total suspended particulates (TSP) to Masson pine (Pinus massoniana L.). Atmos Environ 47: 358-364 
580

Wenzl P, Chaves AL, Patiño GM, Mayer JE, Rao IM (2002) Aluminum stress stimulates the accumulation of organic acids in root apices of Brachiaria species. J Plant Nutr Soil Sci 165: 582-588

Wu RJ, Zhuang J, Huang J, Chen WP (2009) Responses and resistance mechanism of Pinus massoniana under the stresses of simulated acid rain and aluminum. Scientia Silvae Sinicae 45: 22-29

Yang M, Tan L, Xu YY, Zhao YH, Cheng F, Ye SM, Jiang WX (2015) Effect of low pH and aluminum toxicity on the photosynthetic characteristics of different fast-growing Eucalyptus vegetatively propagated clones. PLoS One 10: e0130963

Yang ZB, He C, Ma Y, Herde M, Ding Z (2017) Jasmonic acid enhances Al-induced root growth inhibition. Plant Physiol 173: 1420-1433.

Zhang F, Yan X, Han X, Tang R, Chu M, Yang Y, Yang YH, Zhao F, Fu A, Luan S, Lan W (2019) A defective vacuolar proton pump enhances aluminum tolerance by reducing vacuole sequestration of organic acids. Plant Physiol 181: 743-761.

Zhang HH, Jiang Z, Qin R, Zhang HN, Zou JH, Jiang WS, Liu DH (2014). Accumulation and cellular toxicity of aluminum in seedling of Pinus massoniana. BMC Plant Biol 14: 264.

Zhang M, Lu X, Li C, Zhang B, Zhang C, Zhang XS, Ding Z (2018) Auxin efflux carrier ZmPGP1 mediates root growth inhibition under aluminum stress. Plant Physiol 177: 819-832.

Zhang X, Cui Y, Yu M, Su B, Gong W, Balu`ska F, Komis G, Šamaj J, Shan X, Lin J (2019) Phosphorylation-mediated dynamics of nitrate transceptor NRT1.1 regulate auxin flux and nitrate signaling in lateral root growth. Plant Physiol 181: 480-498. 


\section{Supplementary Files}

This is a list of supplementary files associated with this preprint. Click to download.

- GraphicalAbstract20210311.doc

- Data20210311.doc 